\title{
MODOS DE ORGANIZAÇÃO E ACESSO À INFORMAÇÃO EM PERIÓDICOS ELETRÔNICOS DE CIÊNCIA DA INFORMAÇẪO NO BRASIL
}

\begin{abstract}
Resumo: Uma nova forma de comunicação científica se iniciou com o surgimento dos periódicos científicos, tais como Journal des Sçavans e Philosophical Transactions. Com o advento da internet e do periódico científico eletrônico, aumentou-se o número de periódicos científicos e publicações, acarretando uma maior preocupação com o tratamento da informação. Este estudo teve como objetivo a análise das formas de organização da informação nos websites dos periódicos científicos eletrônicos na área da Ciência da Informação brasileira, com ênfase na recuperação e acesso à informação. A metodologia foi a pesquisa descritiva, com levantamento bibliográfico e documental, com coleta de dados nas páginas dos websites dos periódicos científicos eletrônicos classificados no Qualis A1 e A2. O resultado alcançado foi de que $83 \%$ dos periódicos analisados utilizam softwares livre para editoração científica, $33 \%$ dos periódicos apresentam um índice de termos e o uso de tesauro para a seleção destes termos. Concluiu-se que os periódicos científicos podem explorar mais todos os recursos disponíveis para a organização, recuperação e o acesso à informação do conteúdo publicado.
\end{abstract}

Palavras-chave: Ciência da Informação; organização da informação; representação da informação; comunicação científica; vocabulário controlado.

\author{
Felipe Caldonazzo de Almeida Pereira \\ Mestrando em Ciência da Informação \\ pela Universidade Estadual \\ de Londrina (UEL). \\ fcaldonazzo@gmail.com \\ Maria Rosemary Rodrigues \\ Doutoranda em Ciência da Informação \\ pela Universidade Estadual \\ de Londrina (UEL). \\ rosemaryrodrigues42@gmail.com \\ Brígida Maria Nogueira Cervantes \\ Doutora em Ciência da Informação \\ pela Universidade Estadual \\ Paulista (Unesp), Marília. \\ brigidacervantes@gmail.com
}

\section{ORGANIZING AND ACCESSING INFORMATION IN BRAZILIAN ELECTRONIC SCHOLARLY JOURNALS OF INFORMATION SCIENCE}

\begin{abstract}
The emergence of scholarly journals has introduced a new form of scholarly communication, such as Journal des Sçavans and Philosophical Transactions. Since the Internet and the electronic scholarly journal advent, it has been noticed an expressive increase of scholarly journals and publications, which intensifies the concern towards information treatment. This study main objective was to analyze ways to organize information on Brazilian Information Science's electronic scholarly journals' websites which had their emphasis on information retrieval and its access. The methodology employed was a descriptive research of quali-quantitative nature, and bibliographical documental survey at journals' websites ranked as Qualis A1 and A2. The results indicate that $83 \%$ of the analyzed journals use open source softwares to scientific publishing. Also, $33 \%$ of these journals present index of terms and the usage of thesaurus for these terms selection. It is concluded that scholarly journals are still able to seize the available resources to organizing and access published information.
\end{abstract}

Keywords: Information science; organization of information; information representation; scholarly communication; controlled vocabulary.

\section{INTRODUÇÃO}

Com o surgimento dos periódicos científicos, no século XVII, na Inglaterra e na França, iniciou-se uma nova forma de se realizar a comunicação científica das pesquisas 
produzidas. A mudança na forma de divulgação e disseminação só foi possível graças às invenções de Gutenberg, no século XV, possibilitando a produção de diversos materiais bibliográficos. Porém, os profissionais passariam a lidar em um novo mundo informacional (e desordenado) e deveriam desenvolver formas de se organizar a informação a ser publicada.

Em um sistema de informação, a organização da informação é um processo de arrumação do acervo tradicional ou eletrônico por meio da descrição física e temática de objetos informacionais (CAFÉ; SALES, 2010), visto que tem como produto a representação da informação.

A representação da informação, segundo Dias e Naves (2013), no âmbito do Tratamento Temático da Informação, abarca disciplinas, técnicas, método e processo que visam à descrição física e temática de um documento.

O Tratamento da Informação compreende, também, disciplinas como classificação, indexação e catalogação, incluindo especialidades na área para a utilização de metadados e ontologias. Este tratamento tem como atividades a classificação (extraí o conteúdo de um documento para seu arquivamento no acervo); indexação e catalogação de assuntos (extraem termos ou descritores do documento para a criação de entradas ou pontos de acesso em um catálogo ou índice).

Os instrumentos para o tratamento temático são a Classificação Decimal de Dewey (CDD), a Classificação Decimal Universal (CDU), os tesauros, a Lista de Cabeçalho de Assuntos (LCA), a NBR 6028 (resumo) e a NBR 12676 (métodos de análise dos documentos, determinação de assunto e indexação) (DIAS, 2012; DIAS; NAVES, 2013). Já para o tratamento descritivo temos os instrumentos: Anglo-American Cataloguing Rules (AACR), Resource Description and Access (RDA), MARC21, padrão de metadados e NBR 6023.

Os produtos do tratamento temático são os índices, resumos, palavras-chave, descritores e ponto de acesso, do processo de descrição temática. Para a descritiva temos: referências bibliográficas e catálogos (DIAS, 2012; DIAS; NAVES, 2013).

Além disso, a área do tratamento da informação utiliza-se de linguagens documentárias para se realizar a indexação, o armazenamento e a recuperação da informação. As linguagens documentárias mais conhecidas são os tesauros e os sistemas de classificação bibliográfica e, além destas, Barité (2011) apresenta também como instrumentos para organizar o conhecimento, sendo: Lista de cabeçalho, lista de descritores, lista de autoridade, 
anéis de sinônimos, taxonomias, ontologias, folksonomias, mapas conceituais, mapas de tópicos e os diretórios.

Neste contexto, levando em consideração as técnicas e o conhecimento desenvolvidos na temática da Organização e Representação da Informação e do Conhecimento na área da Ciência da Informação, questionou-se se os periódicos eletrônicos estariam utilizando instrumentos que auxiliam a organização e o acesso à informação nos periódicos científicos eletrônicos.

Este estudo justificou-se em razão de o profissional da informação possuir o conhecimento e a prática para desenvolver instrumentos para a organização, a disponibilização, a disseminação e o acesso à informação nos periódicos científicos eletrônicos. O profissional também possui know-how para realizar uma análise dos requisitos referentes à organização e acesso à informação, reconhecer possíveis fragilidades em um sistema de informação ou aprimorar funcionalidades, visando a recuperação da informação nos periódicos científicos eletrônicos.

Um periódico científico que possua suas funções aprimoradas pode se tornar uma importante fonte de informação para pesquisas vindas a fortalecer o desenvolvimento científico da instituição e, em consequência, o desenvolvimento da sociedade como todo, pois, como se pode constatar na literatura científica, um dos grandes problemas da comunicação científica é a obsolescência do conteúdo publicado, sendo de grande necessidade a identificação e avaliação das formas e dos instrumentos utilizados para a organização do conteúdo científico e o seu posterior acesso, podendo auxiliar no aproveitamento do conhecimento desenvolvido em pesquisas e disseminado por meio de artigos científicos, permitindo o fomento de mais pesquisas científicas nas diversas áreas do conhecimento.

Assim, o objetivo foi analisar as formas de organização da informação nos websites de periódicos científicos eletrônicos em Ciência da Informação, com ênfase na recuperação e no acesso à informação, por meio de procedimentos metodológicos caracterizados pela pesquisa de natureza exploratória e descritiva, utilizando-se de levantamento bibliográfico e documental. 


\section{PERIÓDICO CIENTÍFICO ELETRÔNICO}

O uso dos termos periódico científico ou revista científica variam conforme a categoria profissional. Segundo Stumpf (1998), os bibliotecários preferem utilizar o termo Periódico Científico, enquanto docentes, pesquisadores e estudantes utilizam o termo Revista Científica.

Esses termos advêm do uso de algumas palavras, principalmente do inglês e francês, relacionadas à jornal, ${ }^{1}$ vindo a ter o seu surgimento em Paris e Londres, no século XVII, com a publicação do Journal des Sçavans, uma publicação com escopo nas áreas de humanidades, e com a formação da Philosophical Transactions, da Royal Society, onde se debatia questões filosóficas, mas sem cunho teológico ou político.

O Royal Society tinha como uma de suas principais características a comunicação, pois, os pesquisadores deveriam coletar pessoalmente as informações, conversar sobre as novas pesquisas e resumir as informações coletadas nas viagens pelo mundo. Outra forma de se descobrir publicações no exterior seria a troca de correspondências entre pesquisadores de outras nacionalidades. Assim, com o crescimento e o acúmulo de cartas, houve a necessidade de selecionar as informações mais importantes e organizá-las em uma fonte impressa e distribuí-la.

Com influência direta da "república das letras" na publicação periódica do Journal dês Sçavans (BURKE, 2003; GONÇALVES; RAMOS; CASTRO, 2006; MEADOWS, 1999), determinou-se, após ter conhecimento da publicação francesa, que o Philosophical Transactions fosse impresso na primeira segunda-feira de cada mês, se houvesse material para isso. Também foi determinado que, antes de ser impresso, os textos deveriam ser revistos por seus membros, sendo necessário a aprovação do Conselho (MEADOWS, 1999).

Pode-se, então, perceber as primeiras características que marcariam os periódicos científicos modernos, como sendo uma publicação periódica e regular, contendo os resumos e a avaliação pelos pares. Além destas, Volpato (2008) identifica duas características essenciais para um periódico científico: a existência de análise crítica do conteúdo e ideias com respaldo empírico, com um rígido discurso lógico e coerente.

Com relação a publicação de resumos, Meadows $(1999$, p. 31) lembra que o problema não era em "[...] identificar material pertinente, mas também de ter acesso a ele", portanto, o

\footnotetext{
${ }^{1}$ Significa uma coletânea de artigos científicos, encadernados e distribuídos em um volume único, seguindo intervalos regulares (MEADOWS, 1999).
} 
resumo era utilizado, também, como um substituto ao artigo original. Na década de 1960, as publicações secundárias já eram aceitas por meio dos computadores, sendo os resumos eletrônicos no mesmo molde dos resumos impressos, portanto, uma das primeiras formas de organização e acesso às fontes secundárias se dava por meio das pesquisas por palavras-chave nos títulos dos resumos.

Meadows (1999) lembra que as publicações eram em sua maioria de literatura científica e técnica, mas na década de 1980, as áreas de ciências sociais e humanidades começaram a disponibilizar suas publicações, graças, principalmente, à redução do custo dos microcomputadores.

Foi na década de 1990 que as publicações periódicas científicas começaram a se transformar em periódicos científicos eletrônicos. A primeira fase, que foi de 1990 a 1993, há algumas publicações em CD-ROM e online. Nessa fase surgiram os arquivos de preprints, a World Wide Web (WWW), vindo a despertar o interesse pelas publicações eletrônicas. (TENOPIR et al., 2003).

Na segunda fase, no final da década de 1990 até o ano de 2003, existiam 15 mil periódicos, sendo 12 mil eletronicamente acessíveis. Neste período, o surgimento de algumas iniciativas para lançamento de softwares livres, tais como Dspace (para a construção de repositórios digitais), em 2002, e Open Journal Systems (OJS), em 2001.

$\mathrm{Na}$ terceira fase, de forma embrionária ainda em meados da década de 1990, a Sociedade Americana de Astronomia, a Editora da Universidade de Chicago e a NASA desenvolvem em parceria a NASA Astrophysics Data System, um sistema que permite a busca em metadados, resumos e textos completos, além de acesso à literatura da área desde meados de 1800, além do uso de hyperlinks, citações, estatísticas, gráficos, entre outros. Como resultado do sucesso desta terceira fase, em 2014, já existia um número próximo de 35 mil periódicos científicos, em sua grande maioria somente eletrônicos (STM, 2015).

Essas modificações, no desenvolvimento do periódico científico, foram resultado do surgimento de tecnologias da informação e comunicação para a publicação e editoração científica.

Percebe-se, assim, as necessidades e formas de busca da informação e de acesso à informação pelos pesquisadores e cientistas, também foram se modificando (MÁRDERO ARELLANO; FERREIRA; CAREGNATO, 2005). Essas modificações, no desenvolvimento 
do periódico científico, foram resultado do surgimento de tecnologias da informação e comunicação para a publicação e editoração científica.

\subsection{O OPEN JOURNAL SYSTEMS (OJS)}

O Open Journal Systems (OJS) foi uma das iniciativas de software livre para editoração científica, desenvolvido pelo Public Knowledge Project (PKP), da University of British Columbia, que foi a plataforma escolhida, traduzida para o português e customizada por uma iniciativa do Instituto Brasileiro de Informação em Ciência e Tecnologia (IBICT), inicialmente chamada de Serviço de Editoração Eletrônico de Revistas (SEER), sendo conhecida como OJS/SEER. Segundo Brito e outros (2018), a partir da terceira edição, convencionou-se a padronizar pelo nome OJS.

O software OJS tem o intuito de amparar o padrão editorial, organizar a informação científica e a divulgação em meio eletrônico das publicações nacionais, além de possibilitar a disponibilização dos metadados essenciais das revistas editadas por este software, com o objetivo de diminuir espaços e custos de acesso à informação, vindo a facilitar a localização e o armazenamento da informação incitando a pesquisa. (ALVORCEM, 2010).

O OJS ainda permite a utilização de módulos de extensão para expandir as suas funcionalidades, estes módulos são programas de computador, nomeados de Plugins do Sistema. Além de funcionalidades padrão, como de estatísticas, há a possibilidade de instrumentos para a indexação para o Google Acadêmico, a utilização de plugins próprios ou de terceiros.

Todos estes elementos operam dentro da lógica do protocolo OAI-PMH, utilizado na transferência de dados para repositórios e periódicos eletrônicos de acesso aberto. Segundo Bandeira (2017, p. 35), "Este protocolo tem duas interfaces: interoperabilidade e extensibilidade. A interoperabilidade decorre da obrigatoriedade embutida no protocolo para implementação do padrão Dublin Core (um padrão de metadados); já a extensibilidade, advém da oportunidade de também se criar ou utilizar padrões de metadados diferentes do Dublin Core [...]."

Este software livre permite a aplicação de uma variedade de instrumentos e ferramentas para a organização e o acesso à informação nos periódicos científicos eletrônicos, como o uso de tesauro para compatibilizar os descritores, pesquisas em resumos, plugins que auxiliam o usuário em sua pesquisa, entre outros. 
Portanto, percebe-se a grande importância da filosofia do Acesso Livre segundo estudo recente (SCIENCE-METRIX, 2018), no qual o Brasil é o país com a maior disponibilização de publicações científicas com acesso livre no mundo, cerca de $75 \%$ de sua produção. No tópico a seguir, uma breve discussão sobre metadados, recuperação e acesso à informação.

\section{METADADOS, RECUPERAÇÃO E ACESSO À INFORMAÇÃO}

Com o desenvolvimento dos ambientes digitais para o armazenamento, organização, recuperação e acesso à informação, a utilização de metadados se tornou imprescindível para essas atividades. Schons (2007) lembra que os metadados permitem a descrição de documentos e informações, possibilitam conectá-los a documentos para serem recuperados e manuseados com eficácia, para isso, será necessário definir o padrão de metadados a ser utilizado.

\subsection{METADADOS}

O Dublin Core é um dos padrões de metadados mais utilizado em ambiente web, sendo um padrão criado especificamente para a descrição e recuperação dos conteúdos digitais na $w e b$, visando um trabalho descritivo mais simplificado e eficaz para a recuperação da informação (ALVES, 2010; GRACIO, 2002; MEY; SILVEIRA, 2009).

Segundo Paladini (2014) o Dublin Core possui 15 elementos em nível simples, tais como: Título, autor, Assunto, Descrição, Editor, Contribuidor, Tipo de Recurso, Formato, Identificador do recurso, Fonte, Idioma, Relação, Abrangência e Direitos Autorais. Estes elementos também são utilizados nos websites dos periódicos científicos.

Alves e Santos (2013) apresentam um nível mais qualificado do padrão Dublin Core, além dos 15 elementos de descrição, mais sete elementos adicionais e duas classes qualificadoras. Sendo estes sete elementos: Audiência, Proveniência, Direitos autorais, Métodos de instrução, regime de competência, periodicidade e política. As classes qualificadoras servem para todos os elementos, simples ou qualificados, sendo: Elementos de refinamento e Esquemas de codificação.

Os elementos de refinamento são qualificadores que refinam ou restringem o campo, permitindo que se especifique e amplie o significado dos elementos descritivos. Já os 
esquemas de codificação identificam os esquemas para o valor dos elementos, esquemas como vocabulário controlado, notações de sistema de classificação, entre outros.

Segundo Buckland (2006), o propósito original dos metadados é a descrição de documentos, podendo diferenciar em metadados descritivos, administrativos e de conteúdo. Alguns autores definem os metadados como descritivos, administrativos e estruturais (CAPLAN, 2003; CATARINO, 2009), já outros autores organizam os metadados em quatro tipos: administrativos, descritivos, de conservação, técnicos e de uso (GRACIO, 2002).

Tem-se, também, o Padrão Brasileiro de Metadados para Teses e Dissertações (MTD-BR), padrão criado pelo IBICT, lançado em 2002, visando a normalização e adequação às necessidades de descrição de teses e dissertações arquivadas online. O padrão MTD-BR foi compatibilizado com as normas do Dublin Core e do Eletronic Thesis and Dissertation Metadada Standard (ETD-MS), este último incluindo campos para descrição de titulação, grau (ou nível acadêmico), área de estudo e a instituição que abriga o programa de pós-graduação. (BAPTISTA; FERNEDA, 2016; MEY; SILVEIRA, 2009).

Especificamente sobre os aspectos da representação da informação por meio de metadados, Gracio (2002, p. 113) afirma que “[...] a descrição através de metadados proporciona, entre outras coisas, qualidade tanto para a representação de um recurso, como para o resultado de uma pesquisa.", vindo a facilitar a recuperação e o acesso à informação.

\subsection{RECUPERAÇÃO E ACESSO À INFORMAÇÃO}

O conceito de recuperação da informação surgiu na década de 1950, criado por Calvin Mooers e compreende a representação, o armazenamento, a recuperação e o acesso à informação. Nesse contexto, a Ciência da Informação está diretamente ligada à área da recuperação da informação, esta área é responsável pelo desenvolvimento de produtos, sistemas e serviços, além de introduzir componentes científicos e profissionais.

Os sistemas de recuperação da informação foram se modificando ao longo do tempo, inicialmente, na década de 1940, em forma de um catálogo impresso, pré-coordenado, utilizando-se de índices impressos e catálogos em fichas, posteriormente, na década de 1950, fez uso de palavras-chave, ainda em meios impressos (LANCASTER, 2004; SANTIAGO, 2004). 
Foi somente na década de 1960 que houve um maior "[...] desenvolvimento tecnológico das bibliotecas e sistemas de informação [...]” (SANTIAGO, 2004, p. 29), vindo a possibilitar formas informatizadas de recuperação e intercâmbio de dados e informações, como, por exemplo, a catalogação legível por computador. Assim, na década de 1960, surge um padrão de metadados, o Machine Readable Cataloging (MARC). (FLAMINO, 2006; SANTIAGO, 2004).

Saracevic (1996, p. 46) afirma que na década de 1970 “[...] o paradigma da recuperação da informação deslocou-se em direção a uma contextualização mais ampla, voltando-se para os usuários e suas interações."

Portanto, pode-se perceber que, na área da recuperação da informação, há duas visões, uma voltada para o usuário e outra para os sistemas computacionais, pois, na visão computacional, a preocupação é com a construção de índices, processos de busca e desenvolvimento de algoritmos que tornem a recuperação da informação mais eficiente e precisa, já a visão humanista busca compreender o comportamento do usuário, suas necessidades e sua relação com a organização do sistema. (SANTAREM SEGUNDO, 2010).

Para além da recuperação da informação, atualmente, deve-se levar em consideração o acesso à informação desejada. Sendo o acesso a "[...] possibilidade de o usuário obter, rápida e corretamente, a informação que procura" ou "a capacidade de acessar um recurso independentemente do sistema de acesso a ele.” (CUNHA; CAVALCANTI, 2008, p. 2).

É nesse sentido que Santarem Segundo afirma que (2010, p. 24) “[...] a grande dificuldade no processo de recuperação da informação é conseguir atender à necessidade do usuário, indicando o que é mais ou então menos relevante dentro do contexto de sua consulta a um conjunto de informação." Assim, em busca da solução deste obstáculo, foram desenvolvidos alguns modelos de recuperação da informação.

Sobre o enfoque à questão do acesso, Weitzel (2006, p. 103) afirma que a "[...] ênfase no acesso trouxe alguns aspectos importantes que caracterizam o que vem se apresentando como modelo OA", alguns desses aspectos pode-se destacar: acesso livre à literatura científica e o aumento na preocupação com metadados, interoperabilidade e preservação digital.

Como bem destacaram Merlo e Konrad (2015, p. 34-35), "[...] o acesso se torna moroso ou inexistente quando os registros informacionais não estão ordenados", significando 
que, além do tratamento da informação, o uso de metadados com qualidade e de normas para descrição dos dados aumentam a possibilidade de recuperação dos documentos.

\section{PROCEDIMENTOS METODOLÓGICOS}

Este estudo realizou uma pesquisa de natureza descritiva e técnica de pesquisa documental, com uma abordagem qualiquantitativa. Este estudo envolveu a coleta de dados, no período entre os dias 07 e 21 de novembro de 2018, nos websites dos periódicos científicos eletrônicos classificados no Qualis em A1 (Transinformação, Perspectivas em Ciência da Informação e Informação \& Sociedade) e A2 (Informação \& Informação, Encontros Bibli e Em Questão) e a análise das informações disponibilizadas para os usuários e os instrumentos utilizados por estes periódicos. Cabendo ressaltar que houve uma nova coleta de dados, em junho de 2020, para verificar possíveis atualizações nos periódicos eletrônicos.

A pesquisa teve quatro etapas, sendo a primeira etapa a seleção dos periódicos, constituindo o corpus de análise; a segunda etapa foi a coleta de dados da organização dos websites dos periódicos eletrônicos, com o preenchimento de formulários com as respectivas informações, conforme o Quadro 1.

\begin{tabular}{|l|c|c|c|}
\multicolumn{2}{c}{ Quadro 1: Formulário para conteúdo de acesso geral } \\
\hline PERIÓDICO & PÁGINA INICIAL & PÁGINA SUMÁRIO & $\begin{array}{c}\text { PÁGINA DO } \\
\text { ARTIGO }\end{array}$ \\
\hline & & & \\
\hline & & & \\
\hline
\end{tabular}

Fonte: elaborado por Pereira (2018).

A terceira etapa foi a coleta de dados sobre o uso de vocabulário controlado e outros instrumentos para organização e acesso à informação, conforme o Quadro 2. 
Quadro 2: Formulário para vocabulário controlado e outros instrumentos

\begin{tabular}{|c|c|c|c|c|c|c|c|c|c|}
\hline \multirow{3}{*}{ Periódico } & \multicolumn{5}{|c|}{ Instrumento Organização } & \multicolumn{4}{|c|}{ Instrumento Acesso } \\
\hline & \multirow[b]{2}{*}{ ITerm } & \multirow[b]{2}{*}{ vC } & \multirow[b]{2}{*}{ NT } & \multirow[b]{2}{*}{ IP } & \multirow[b]{2}{*}{ IT } & \multicolumn{2}{|c|}{ Instrumento Leitura } & \multirow{2}{*}{$\begin{array}{l}\text { D } \\
\mathbf{O} \\
\text { I } \\
\end{array}$} & \multirow[b]{2}{*}{ ORCID } \\
\hline & & & & & & PDF & $\begin{array}{c}\text { HTM } \\
\text { L }\end{array}$ & & \\
\hline & & & & & & & & & \\
\hline & & & & & & & & & \\
\hline & & & & & & & & & \\
\hline
\end{tabular}

Fonte: elaborado por Pereira (2018).

ITerm = Índice de Termos $/$ VC = Vocabulário Controlado / NT = Nuvem de Tags $/$ IP = Instrumento Próprio / $\mathrm{IT}=$ Instrumento de Terceiros $/ \mathrm{PDF}=$ Leitor PDF online $/ \mathrm{OF}=$ Outros Formatos $/$ Ipers = Identificador Persistente.

E a quarta, e última etapa, foi a análise dos dados coletados destes periódicos e sua posterior comparação. Esta última etapa está presente na seção 6, sobre análise e resultados.

\section{ANÁLISE E RESULTADOS}

$\mathrm{Na}$ análise de dados, destaca-se a forma como as informações estão disponibilizadas e os instrumentos utilizados nas páginas dos periódicos científicos eletrônicos. A seguir, apresentam-se nas páginas dos periódicos científicos, conforme demonstra-se no Quadro 3.

Quadro 3: Páginas dos periódicos científicos

\begin{tabular}{|c|c|c|c|}
\hline $\begin{array}{c}\text { PERIÓDICO } \\
\text { Transinformação }\end{array}$ & PÁGINA INICIAL & PÁGINA SUMÁRIO & PÁGINA ARTIGO \\
\hline \multirow[t]{2}{*}{ Transinformação } & $\begin{array}{ll}\text { Menu superior: } \\
\text { - } \\
\text { - } \quad \text { pesquisa por autor } \\
\text { - } \quad \text { pesquisa por assunto } \\
\text { - } \quad \text { pesquisa avançada }\end{array}$ & $\begin{array}{ll}- & \text { acesso às } \\
& \text { publicações } \\
& \text { (HTML ou } \\
& \text { PDF) } \\
\text { - } & \text { resumo } \\
\end{array}$ & $\begin{array}{ll}- & \text { acesso ao DOI } \\
- & \text { acesso ao ORCID } \\
- & \text { acesso ao artigo em } \\
& \text { HTML }\end{array}$ \\
\hline & $\begin{array}{ll}\text { Menu lateral: } \\
\text { • } & \text { sobre a revista } \\
\text { - } & \text { instruções aos autores } \\
\text { - } & \text { métricas }\end{array}$ & & $\begin{array}{cl}\text { Menu lateral: } \\
\text { - } & \text { métricas do artigo } \\
\text { - } & \text { artigo em PDF ou } \\
& \text { XML } \\
\text { - } & \text { referências } \\
\text { - } & \text { como citar } \\
\text { - } & \text { tradução } \\
& \text { automática } \\
\text { - } & \text { permalink }\end{array}$ \\
\hline $\begin{array}{l}\text { Perspectivas em } \\
\text { Ciência da } \\
\text { Informação }\end{array}$ & $\begin{array}{ll}\text { Menu superior: } \\
\text { - } & \text { página principal } \\
\text { - } & \text { sobre a revista } \\
\text { - } & \text { acesso (do usuário) } \\
\text { - } & \text { cadastro (do usuário) } \\
\text { - } & \text { pesquisa } \\
\text { - } & \text { notíciaçãa atual/anterior } \\
\end{array}$ & $\begin{array}{ll}\text { - } & \text { sumário da } \\
\text { edição } \\
\text { - } \\
\text { acesso ao } \\
\text { resumo } \\
\text { - acesso ao PDF } \\
\text { do artigo }\end{array}$ & $\begin{array}{ll}- & \text { título } \\
\text { - } & \text { autoria } \\
\text { - } & \text { resumo } \\
\text { - } & \text { palavras-chave } \\
\text { - } & \text { texto em PDF } \\
\text { - } & \text { referências }\end{array}$ \\
\hline
\end{tabular}




\begin{tabular}{|c|c|c|c|}
\hline & $\begin{array}{cl}\text { Menu lateral: } \\
\text { - } & \text { tamanho da fonte } \\
\text { - } & \text { Idioma } \\
& \text { pesquisa (autor, título, } \\
& \text { resumo, termos } \\
& \text { indexados e texto } \\
& \text { completo) } \\
\text { - } & \text { nuvem de tags } \\
\text { - } & \text { informações da OJS }\end{array}$ & & $\begin{array}{ll}\text { Menu lateral: } \\
\text { - } \\
\text { - } \quad \text { Idiomanho da fonte } \\
\text { - } \quad \text { impressão } \\
\text { - } \quad \text { metadados } \\
\text { - } \quad \text { como citar } \\
\text { - } \quad \text { enviar email } \\
\text { - informações sobre } \\
\text { autores }\end{array}$ \\
\hline \multirow[t]{2}{*}{$\begin{array}{l}\text { Informação \& } \\
\text { Sociedade }\end{array}$} & $\begin{array}{ll}\text { Menu superior: } \\
\text { - } & \text { página principal } \\
\text { - } & \text { sobre a revista } \\
\text { - } & \text { acesso (do usuário) } \\
\text { - } & \text { cadastro (do usuário) } \\
\text { - } & \text { pesquisa } \\
\text { - } & \text { notícicaçãa atual/anterior } \\
\text { - } & \text { acesso ao programa de } \\
& \text { pós-graduação } \\
\end{array}$ & $\begin{array}{ll}\text { - } & \text { sumário da } \\
\text { edição } \\
\text { - } & \text { acesso ao } \\
& \text { resumo } \\
\text { - } & \text { acesso ao PDF } \\
\text { do artigo }\end{array}$ & $\begin{array}{ll}\text { - } & \text { título } \\
\text { - } & \text { autoria } \\
\text { - } & \text { resumo } \\
\text { - } & \text { palavras-chave } \\
\text { - } & \text { texto em PDF } \\
\text { - } & \text { DOI } \\
\text { - } & \text { comentários } \\
& \text { (usuário) }\end{array}$ \\
\hline & $\begin{array}{ll}\text { Menu lateral: } \\
\text { - } & \text { informações da OJS } \\
\text { - } & \text { idioma } \\
& \text { pesquisa (autor, título, } \\
& \text { resumo, termos } \\
& \text { indexados e texto } \\
& \text { completo) } \\
\text { - } & \text { tamanho da fonte } \\
\text { - } & \text { nuvem de tags } \\
\end{array}$ & & - $\quad$ sem ferramentas \\
\hline \multirow[t]{2}{*}{$\begin{array}{l}\text { Informação \& } \\
\text { Informação }\end{array}$} & $\begin{aligned} & \text { Menu lateral: } \\
& \text { - } \text { idioma } \\
& \text { - } \text { Tamanho da fonte } \\
& \text { - } \text { pesquisa (autor, título, } \\
& \text { resumo, termos } \\
& \text { indexados e texto } \\
& \text { completo) } \\
& \text { - } \text { procurar autor, edição } \\
& \text { ou título } \\
& \text { - } \text { nuvem de tags } \\
&\end{aligned}$ & $\begin{array}{ll}\text { - } & \text { sumário da } \\
\text { edição } \\
\text { - } \\
\text { acesso ao } \\
\text { resumo } \\
\text { - } \begin{array}{l}\text { acesso ao PDF } \\
\text { do artigo }\end{array}\end{array}$ & $\begin{array}{ll}\text { - } & \text { impressão } \\
\text { - } & \text { metadados } \\
\text { - } & \text { como citar } \\
\text { - } & \text { pesquisar referência } \\
\text { - } & \text { enviar artigo por } \\
& \text { email } \\
\text { - enviar email para } & \text { autor }\end{array}$ \\
\hline & $\begin{array}{l}\text { Menu superior: } \\
\text { - } \quad \text { página principal } \\
\text { - } \text { sobre a revista } \\
\text { - } \text { acesso (do usuário) } \\
\text { - } \text { cadastro (do usuário) } \\
\text { - } \text { estatísticas } \\
\text { - publicação atual/anterior } \\
\text { - notícias } \\
\text { - } \text { portal de revistas da } \\
\text { - } \quad \text { artigos mais citados }\end{array}$ & & $\begin{array}{ll} & \text { título } \\
\text { - } & \text { autoria } \\
\text { - } & \text { resumo } \\
\text { - } & \text { palavras-chave } \\
\text { - } & \text { texto em PDF } \\
\text { - } & \text { referências } \\
\text { - } & \text { DOI }\end{array}$ \\
\hline Encontros Bibli & $\begin{array}{ll}\text { Menu lateral: } \\
\text { - } & \text { login usuário } \\
& \text { pesquisa conteúdo da } \\
& \text { revista (autor, título, } \\
& \text { resumo, termos } \\
& \text { indexados e texto } \\
& \text { completo) } \\
\text { - } & \text { procurar autor, edição } \\
& \text { ou título } \\
\text { - } & \text { tamanho da fonte } \\
\text { - } & \text { Idioma } \\
\text { - } & \text { Informações para } \\
\end{array}$ & $\begin{array}{ll}- & \text { sumário da } \\
\text { edição } \\
\text { - } \\
\text { acesso ao } \\
\text { resumo } \\
\text { - } \begin{array}{l}\text { acesso ao PDF } \\
\text { do artigo }\end{array} \\
\end{array}$ & \begin{tabular}{ll} 
- & \multicolumn{2}{l}{ Impressão do artigo } \\
- & metadados \\
- & como citar \\
- & pesquisar referência \\
- & política de \\
& avaliação \\
- enviar artigo por & email \\
- enviar email para \\
- autor \\
Informações sobre \\
os autores \\
\end{tabular} \\
\hline
\end{tabular}




\begin{tabular}{|c|c|c|c|}
\hline & $\begin{array}{ll} & \text { leitores, autores e } \\
& \text { bibliotecários } \\
\text { - } & \text { nuvem de tags } \\
\text { - } & \text { Informações do OJS }\end{array}$ & & \\
\hline & $\begin{array}{ll}\text { Menu superior: } \\
\text { - } \\
\text { - } \\
\text { - } & \text { sobre a revina principal } \\
\text { - } & \text { cadastro (do usuário) } \\
\text { - } & \text { pesquisa } \\
\text { - } & \text { publicaçãa atual/anterior } \\
\text { - notícias } \\
\text { - diretrizes para autores e } \\
& \text { éticas } \\
\end{array}$ & & $\begin{array}{ll}\text { - } & \text { título } \\
\text { - } & \text { autoria } \\
\text { - } & \text { resumo } \\
\text { - } & \text { palavras-chave } \\
\text { - } & \text { texto em PDF } \\
\text { - } & \text { DOI }\end{array}$ \\
\hline \multirow[t]{2}{*}{ Em Questão } & $\begin{array}{cl}\text { Menu lateral: } \\
\text { - } & \text { idioma } \\
\text { - } & \text { login usuário } \\
\text { - } & \text { pesquisa conteúdo da } \\
& \text { revista (autor, título, } \\
& \text { resumo, termos } \\
& \text { indexados e texto } \\
& \text { completo) } \\
\text { - } & \text { procurar autor, edição } \\
& \text { ou título } \\
\text { - } & \text { informações do OJS } \\
\text { - } & \text { tamanho da fonte } \\
\end{array}$ & $\begin{array}{ll}\text { - } & \text { sumário da } \\
& \text { edição } \\
\text { - } & \text { acesso ao } \\
& \text { resumo } \\
\text { - } & \text { acesso ao PDF } \\
\text { do artigo }\end{array}$ & $\begin{array}{ll}\text { - } & \text { título } \\
\text { - } & \text { autoria } \\
\text { - } & \text { resumo } \\
\text { - } & \text { palavras-chave } \\
\text { - } & \text { texto em PDF } \\
\text { - } & \text { DOI }\end{array}$ \\
\hline & $\begin{array}{ll}\text { Menu superior: } \\
\text { - } & \text { página principal } \\
\text { - } & \text { sobre a revista } \\
\text { - } & \text { acesso/cadastro (do } \\
& \text { usuário) } \\
\text { - } & \text { pesquisa } \\
\text { - } & \text { publicação atual/anterior } \\
\text { - notícias } \\
\text { - diretrizes para autores e } \\
\text { éticas }\end{array}$ & & $\begin{array}{ll}- & \text { sem ferramentas no } \\
\text { menu lateral }\end{array}$ \\
\hline
\end{tabular}

Fonte: elaborado por Pereira (2018).

No Quadro 3, a primeira coluna refere-se aos seis periódicos analisados: Transinformação; Perspectivas em Ciência da Informação; Informação \& Sociedade; Informação \& Informação; Encontros Bibli e Em Questão.

Nas páginas principais dos periódicos científicos pode-se visualizar um menu superior e um menu lateral, onde se tem acesso às informações sobre o periódico, possibilitando realizar uma pesquisa rápida, acessar a edição mais atual, entre outros. Ao selecionar uma edição, apresenta-se uma página com o sumário, com a listagem das publicações. Ao selecionar uma determinada publicação, acessa-se a página do artigo, possibilitando o acesso ou o download do artigo, cabe ressaltar que ao se acessar a página do artigo, alguns periódicos 
disponibilizam ferramentas extras no menu lateral, permitindo a impressão, o contato com os autores, a visualização dos metadados, a disponibilização da referência em diversos formatos, entre outros.

Dos periódicos científicos eletrônicos analisados, $83 \%$ utilizam o software livre da OJS, permitindo um mesmo padrão na estrutura das páginas dos periódicos, o que torna a busca por informações mais familiarizadas pelos usuários ou autores, como o acesso aos menus com informações para os autores ou acesso às edições antigas ou atuais, assim como as ferramentas que permitem por buscas mais gerais ou específicas, por exemplo, sendo o periódico Transinformação o único a utilizar o software de editoração da SciELO.

Todos os periódicos analisados disponibilizam um sumário para cada edição, onde pode-se acessar os resumos, a autoria e o Digital Object Identifier (DOI). Isto significa que os periódicos estão preocupados com as melhores práticas de editoração científica. Porém, somente o periódico Informação \& Informação exige a apresentação de um resumo estruturado, em que se explicita a introdução, objetivo, métodos, resultados e conclusão, conforme a NBR 6028.

Foram analisados os instrumentos utilizados pelos periódicos para a organização e o acesso à informação. Sendo que os instrumentos de organização auxiliam na seleção, apresentação e identificação do conteúdo das publicações como (por exemplo, na seleção de palavras-chave/descritores ou na construção de índices de termos).

Já os instrumentos para o acesso auxiliam que os usuários acessem com mais facilidade o conteúdo da publicação (por exemplo, disponibilizar a leitura on-line). Conforme o manual do OJS (PUBLIC KNOWLEDGE PROJECT, 2006), diversos plug-ins podem ser utilizados.

Após a coleta dos dados sobre os instrumentos utilizados para a organização e o acesso à informação, pode-se perceber, pelo formulário para coleta de instrumentos, conforme Quadro 4, que não há um padrão para utilização de instrumentos de organização da informação. 
Quadro 4: Formulário para coleta de instrumentos

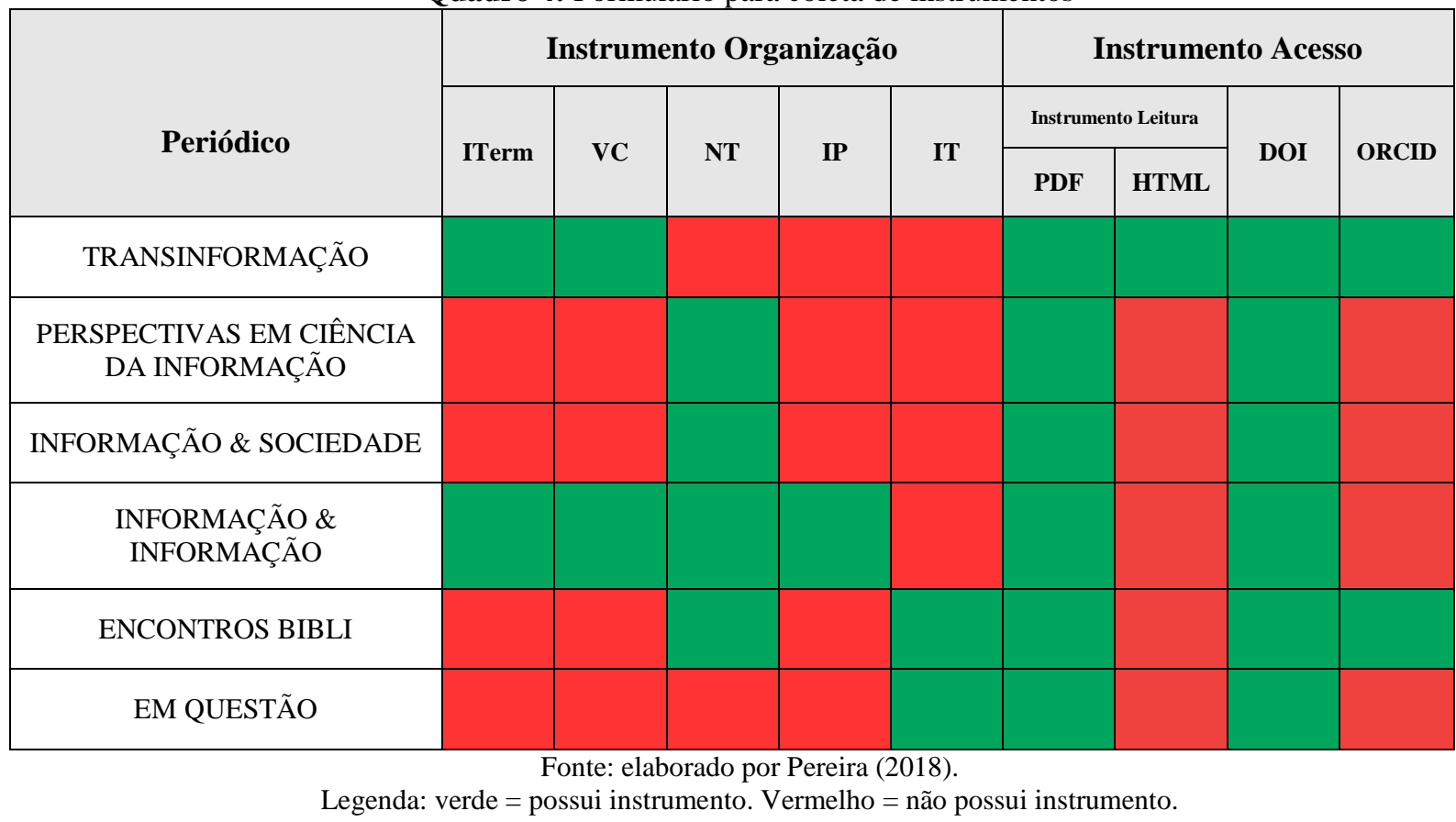

Explicando o quadro acima, observou-se que, dos seis periódicos analisados, somente dois (Transiformação e Informação \& Informação) disponibilizam um índice de termos, que auxiliam os usuários em suas pesquisas. Isso equivale a somente $33 \%$ dos periódicos analisados. Em relação ao uso de um Vocabulário Controlado, o uso do Tesauro, como bem lembrado por Dias e Naves (2013), é um instrumento para o tratamento temático da informação, porém, somente dois (Transiformação e Informação \& Informação) dos periódicos informam sobre o uso deste instrumento, que auxilia tanto na pesquisa quanto na identificação de termos pelos autores no momento da submissão da publicação. O uso de descritores otimiza o processo de recuperação da informação em um contexto no qual a interoperabilidade entre os sistemas de informação é tão debatida, principalmente após o surgimento do Movimento Acesso Livre (BANDEIRA, 2017).

Sobre o instrumento nuvem de tags, este é um plugin padrão do OJS, onde são disponibilizadas as palavras-chave mais indexadas pelos autores. As palavras-chave como lembra Lancaster (2004), é uma importante ferramenta para a recuperação da informação. Somente dois periódicos (Transiformação e Em Questão) não utilizam este instrumento, porém, fica evidente que o emprego deste instrumento não é o suficiente, já que em todos os periódicos aparecem palavras-chaves duplicadas, significando que um mesmo termo é indexado de maneiras diferentes. 
O quarto instrumento de organização identificado está presente em somente um periódico eletrônico, sendo um instrumento que compatibiliza e padroniza os termos indexados em sua base de dados, disponibilizando, além de um índice de termos, um vocabulário controlado do próprio periódico. O controle do vocabulário, conforme Lancaster (2004) afirma, disponibiliza uma lista de termos autorizados, auxiliando na recuperação da informação.

No quesito instrumento de acesso, todos os periódicos disponibilizam a leitura online direto na página, por meio do Portable Document Format (PDF). Porém, cabe ressaltar, que somente um periódico disponibiliza a leitura por HyperText Markup Language (HTML). Esta funcionalidade facilita o acesso por meio de um dispositivo móvel, onde a tela é menor, assim, o texto pode se adequar ao tamanho desejado pelo usuário.

Em relação aos identificadores persistentes, todos os periódicos empregam o DOI para suas publicações, acompanhando as melhores práticas de editoração científica para a identificação de um objeto digital. Cabe ressaltar que o periódico Transinformação disponibiliza um identificador persistente exclusivo da SciELO, chamado Permalink. Sobre o ORCID, identificador persistente para os pesquisadores, somente dois periódicos apresentam esta ferramenta ou exigem dos autores para a publicação.

Conforme os dados coletados entre os dias 07 e 21 de novembro de 2018, somente os periódicos Transinformação e Informação \& Informação disponibilizam um índice de termos indexados. Estes instrumentos auxiliam na apresentação das informações dos conteúdos publicados. No caso do periódico Informação \& Informação, o índice ainda apresenta a quantidade de vezes que os termos foram indexados.

O índice gerado no periódico Informação \& Informação apresenta, além da lista de termos, o vocabulário controlado da revista e a quantidade de artigos com o termo indexado. Especificamente sobre a Informação \& Informação, este periódico compatibiliza os termos indexados com o Tesauro Brasileiro de Ciência da Informação, do Instituto Brasileiro de Informação em Ciência e Tecnologia (IBICT) (PINHEIRO; FERREZ, 2014), o que permite gerar um Vocabulário Controlado próprio para a revista, apresentando, inclusive, o perfil do periódico, graças ao instrumento VCPC Tools (SANTOS, 2015).

O perfil do periódico permite a visualização das áreas de estudo e pesquisa dos artigos publicados, sendo que as pesquisas mais publicadas se encontram nas áreas de: 1) Epistemologia da Ciência da Informação; 2) Organização do Conhecimento e Recuperação da 
Informação; 3) Gestão da Informação; 4) Comunicação e Acesso à Informação e 5) Tecnologias da Informação e Comunicação com, respectivamente, 206, 209, 195, 190 e 178 artigos publicados.

Outro ponto importante a ser ressaltado, é sobre os periódicos Em Questão, Informação \& Informação e Encontros Bibli, que disponibilizam uma ferramenta de organização e acesso. Ambos os periódicos incorporaram suas publicações ao Google Acadêmico, facilitando além do acesso, a organização deste acervo, como, por exemplo, disponibilizar os periódicos mais citados, obter dados bibliométricos, como índice $\mathrm{H}$, entre outros.

Assim, observou-se que a maioria dos periódicos científicos eletrônicos analisados não disponibilizam algum tipo de controle de vocabulário, mas exploram os recursos eletrônicos disponibilizados pelos softwares de editoração, como a apresentação dos termos mais indexados e o acesso diretamente do navegador aos documentos publicados.

\section{CONSIDERAÇÕES FINAIS}

Os periódicos científicos eletrônicos se tornaram uma das principais fontes de informação para as pesquisas científicas, para tanto, esta pesquisa teve como objetivo analisar as formas de organização da informação com foco na recuperação e acesso à informação.

O resultado desta pesquisa reforça a necessidade de investigações futuras em um universo mais amplo, onde poderá ser pesquisada a utilização de instrumentos e ferramentas nos websites de outros periódicos, inclusive de outras áreas do conhecimento. $\mathrm{O}$ uso de tesauros em um formato eletrônico pode dar agilidade no processo de compatibilização dos termos. Pode-se pesquisar o uso de ontologias, o que permitirá a comparação dos resultados segundo diferentes processos utilizados. Pesquisas futuras permitirão explorar as diversas técnicas para o tratamento da informação que auxiliarão a área da comunicação científica, facilitando a disseminação do conhecimento desenvolvido nas universidades.

Portanto, pode-se perceber que a Ciência da Informação tem importantes contribuições para a disseminação e o desenvolvimento da ciência como um todo, tanto no desenvolvimento de técnicas, instrumentos entre outras tecnologias, quanto na própria organização do conteúdo publicado, auxiliando na recuperação e acesso à informação desejada. 


\section{REFERÊNCIAS}

ALVES, R. C. V. Metadados como elementos do processo de catalogação. 2010. 132 f. Tese (Doutorado em Ciência da Informação) - Faculdade de Filosofia e Ciências, Universidade Estadual Paulista, Marília, 2010.

ALVES, R. C. V.; SANTOS, P. L. V. A. C. Metadados no domínio bibliográfico. Rio de Janeiro: Intertexto, 2013.

ALVORCEM, R. M. O sistema eletrônico de editoração de revistas e sua navegabilidade: um estudo no fluxo do processo editorial no portal de periódicos da UFSC. 2010. $194 \mathrm{f}$. Dissertação (Mestrado em Ciência da Informação) - Universidade Federal de Santa Catarina. 2010. Disponível em:

https://repositorio.ufsc.br/xmlui/bitstream/handle/123456789/93686/284470.pdf. Acesso em: 14 maio 2018.

BANDEIRA, P. M. Movimento de Acesso Aberto no Brasil: contribuição do Instituto Brasileiro de Informação em Ciência e Tecnologia a partir da implementação do Sistema Eletrônico de Editoração de Revistas. 2017. 107 f. Dissertação (Mestrado em Ciência da Informação) - Universidade Federal da Paraíba. 2017. Disponível em:

http://tede.biblioteca.ufpb.br:8080/bitstream/tede/9702/2/ArquivoTotal.pdf. Acesso em: 16 maio 2018.

BAPTISTA, F.; FERNEDA, E. O padrão brasileiro de metadados para teses e dissertações MTD-BR: aspectos e contribuições. In: SEMINÁRIO EM CIÊNCIA DA INFORMAÇÃO SECIN, 6., 2016, Londrina. Anais [...]. Londrina: UEL, 2016. p. 1028-1042. Disponível em: http://www.uel.br/eventos/cinf/index.php/secin2016/secin2016/paper/viewFile/323/202. Acesso em: 15 jan. 2018.

BARITÉ, M. R. Sistemas de organización del conocimiento: una tipologia actualizada. Informação e Informação, Londrina, v. 16, n. 3, p. 122-139, jan./jun. 2011. Disponível em: http://www.uel.br/revistas/uel/index.php/informacao/article/view/9952/9286. Acesso em: 16 jul. 2018.

BRASIL. Coordenação de Aperfeiçoamento de Pessoal de Nível Superior. Considerações sobre Qualis periódicos: Comunicação e Informação. 2017. Disponível em:

http://capes.gov.br/images/stories/download/avaliacao/relatorios-finais-quadrienal2017/20122017-Comunicacao-quadrienal.pdf. Acesso em: 26 nov. 2018.

BRITO, R. F. et al. Guia do usuário do OJS 3. Brasília: Ibict, 2018. Disponível em: https://bibliotecadigital.mdh.gov.br/jspui/handle/192/252. Acesso em: 10 jun. 2020.

BUCKLAND, M. K. Descrição e pesquisa: metadados como infra-estrutura. Brazilian Journal of Information Science, Marília, v. 0, n. 0, p. 3-15, jul./dez. 2006. Disponível em: http://www2.marilia.unesp.br/revistas/index.php/bjis/article/viewFile/26/25. Acesso em: 5 jan. 2018. 
BURKE, P. Uma história social do conhecimento: de Gutemberg a Diderot. Rio de Janeiro: Jorge Zahar, 2003.

CAFÉ, L. M. A.; SALES, R. Organização da informação: Conceitos básicos e breve fundamentação teórica. In: ROBREDO, J.; BRÄSCHER, M. (org.). Passeios no Bosque da Informação: estudos sobre representação e organização da informação e do conhecimento EROIC. Brasília DF: IBICT, 2010. Disponível em:

http://www2.senado.leg.br/bdsf/item/id/189812. Acesso em: 24 jun. 2018.

CAPLAN, P. Metadata fundamentals for all librarians. Chicago: American Library Association, 2003.

CATARINO, M. E. Integração das folksonomias aos metadados: identificação de novos elementos de metadados como contributo para a descrição de recursos em repositórios. 2009. 232 f. Tese (Doutorado em Tecnologias e Sistemas de Informação) - Departamento de Sistemas de Informação, Escola de Engenharia, Universidade do Minho, Guimarães, 2009.

CUNHA, M. B.; CAVALCANTI, C. R. Dicionário de Biblioteconomia e Arquivologia. Brasília: Briquet de Lemos, 2008.

DIAS, E. W.; NAVES, M. M. L. Análise de assunto: teoria e prática. 2.ed. Brasília: Briquet de Lemos, 2013.

DIAS, G. D. A organização temática da informação em periódicos científicos eletrônicos: atribuição de palavras-chave na biblioteconomia e na ciência da informação. $2012.159 \mathrm{f}$.

Dissertação (Mestrado em Gestão da Informação - MP) - Universidade Estadual de Londrina, 2012.

FLAMINO, A. N. MARCXML: um padrão de descrição para recursos informacionais em Open Archives. 2006. 164 f. Dissertação (Mestrado em Ciência da Informação) - Faculdade de Filosofia e Ciências, Universidade Estadual Paulista, Marília, 2006.

GONÇALVES, A.; RAMOS, L. M. S. V. C.; CASTRO, R. C. F. Revistas científicas: características, funções e critérios de qualidade. In: POBLACION, D. A.; WITTER, G. P.; SILVA, J. F. M. (org.). Comunicação e produção científica: contexto, indicadores e avaliação. São Paulo: Angellara, 2006.

GRACIO, J. C. A. Metadados para a descrição de recursos da Internet: o padrão Dublin Core, aplicações e a questão da interoperabilidade. 2002. 127 f. Dissertação (Mestrado em Ciência da Informação) - Faculdade de Filosofia e Ciências, Universidade Estadual Paulista, Marília, 2002.

LANCASTER, F. W. Indexação e resumos: teoria e prática. 2. ed. Brasília: Briquet de Lemos, 2004.

MÁRDERO ARELLANO, M. A..; FERREIRA, S. M. S. P.; CAREGNATO, S. E. Editoração eletrônica de revistas científicas com suporte do Protocolo OAI. In: FERREIRA, S. M. S. P.; TARGINO, M. G. (org.). Preparação de revistas científicas: teoria e prática. São Paulo: Reichmann \& Autores, 2005. 
MEADOWS, A. J. A comunicação científica. Brasília: Briquet de Lemos, 1999.

MERLO, F.; KONRAD, G. V. R. Documento, história e memória: a importância da preservação do patrimônio documental para o acesso à informação. Informação \& Informação, Londrina, v. 20, n. 1, p. 26-46, jan./abr. 2015. Disponível em: http://www.uel.br/revistas/uel/index.php/informacao/article/view/18705/pdf_43. Acesso em: 29 nov. 2018.

MEY, E. S. A.; SILVEIRA, N. C. Catalogação no plural. Brasília: Briquet de Lemos, 2009.

PALADINI, F. Dublin Core: o guia dos iniciantes. 2014. Disponível em: http://paladini.github.io/dublin-core-basics/lang/pt-br/index.html. Acesso em: 20 jun. 2018.

PEREIRA, Felipe Caldonazzo de Almeida. Periódicos científicos eletrônicos: modos de organização e acesso à informação. 2018. Trabalho de Conclusão de Curso (Graduação em Biblioteconomia) - Universidade Estadual de Londrina, Londrina, 2018.

PINHEIRO, L. V. R.; FERREZ, H. D. Tesauro Brasileiro de Ciência da Informação. Rio de Janeiro; Brasília: Instituto Brasileiro de Informação em Ciência e Tecnologia (IBICT), 2014.

PUBLIC KNOWLEDGE PROJECT. OJS em uma hora: uma introdução ao Sistema Eletrônico de Editoração de Revistas SEER/OJS - versão 2.1.1. Tradução de Ramón Martins Sodoma da Fonseca. Brasília: IBICT, 2006. Disponível em:

https://pkp.sfu.ca/files/ojs_em_uma_hora.pdf. Acesso em: 28 nov. 2018.

SANTAREM SEGUNDO, J. E. Representação iterativa: um modelo para repositórios digitais. 2010. 224 f. Tese (Doutorado) - Faculdade de Filosofia e Ciências, Universidade Estadual Paulista, Marília, 2010. Disponível em: https://repositorio.unesp.br/handle/11449/103346. Acesso em: 06 maio 2018.

SANTIAGO, M. C. C. Metadados para recuperação da informação em ambiente virtual. 2004. Dissertação (Mestrado em Ciência da Informação) - Escola de Comunicação, Universidade Federal do Rio de Janeiro, Rio de Janeiro, 2004.

SANTOS, J. C. F. Vocabulário controlado em periódicos científicos eletrônicos: uma proposta de controle de termos. 2015. 144 f. Dissertação (Mestrado em Ciência da Informação) - Universidade Estadual de Londrina. Centro de Educação, Comunicação e Artes. Programa de Pós-Graduação em Ciência da Informação, Londrina, 2015.

SARACEVIC, T. Ciência da informação: origem, evolução e relações. Perspectivas em Ciência da Informação, Belo Horizonte, v. 1, n. 1, p. 41-62, jan./jun. 1996.

SCHONS, C. H. O volume de informações na internet e sua desorganização: reflexões e perspectivas. Informação \& Informação, Londrina, v. 12, n. 1, p. 50-65, jan./jun. 2007. Disponível em: http://www.uel.br/revistas/uel/index.php/informacao/article/view/1748/1497. Acesso em: 29 nov. 2018. 
SCIENCE-METRIX. Analytical support for bibliometrics indicators: open access availabitity of scientific publications. Montreal: Science-Metrix, 2018. Disponível em: http://www.science-metrix.com/sites/default/files/science-metrix/publications/sciencemetrix_open_access_availability_scientific_publications_report.pdf. Acesso em: 30 nov. 2018 .

SOUZA, M. Produção científica brasileira: caminhos norteadores para instituições de fomento a pesquisa. Brazilian Journal of Information Science: Research Trends. Marília, v. 12, n. 1, p. 46-60. 2018. Disponível em:

http://www2.marilia.unesp.br/revistas/index.php/bjis/article/view/7187/5006. Acesso em: 17 jun. 2018.

STM: International Association of Scientific, Technical and Medical Publishers. The STM report: an overview of scientific and scholarly jounal publishing. STM: Haia, 2015.

Disponível em: https://www.stm-assoc.org/2015_02_20_STM_Report_2015.pdf. Acesso em 30 nov. 2018

STUMPF, I. R. C. Reflexões sobre as revistas brasileiras. Intexto, Porto Alegre, v. 1, n. 3, p. 1-10, jan./jun. 1998. Disponível em:

http://www.seer.ufrgs.br/intexto/article/viewFile/3369/3953. Acesso em: 17 jun. 2018.

TENOPIR, C. et al. Patterns of journal use by scientists through three evolutionary phases. DLib Magazine, [s. l.], v. 9, n. 5, maio 2003. Disponível em:

http://dlib.org/dlib/may03/king/05king.html. Acesso em: 6 jun. 2018.

VOLPATO, G. Publicação científica. 3. ed. São Paulo: Cultura Acadêmica, 2008.

WEITZEL, S. R. Fluxo da informação científica. In: POBLACION, D. A.; WITTER, G. P.; SILVA, J. F. M. (org.). Comunicação e produção científica: contexto, indicadores e avaliação. São Paulo: Angellara, 2006. 